\title{
Oxygen diffusion in oxide thin films grown on $\mathrm{SrTiO}_{3}$
}

\author{
Christof W. Schneider $\odot,{ }^{1, *}$ Max Döbeli, ${ }^{2}$ Christoph Richter $\odot,{ }^{3}$ and Thomas Lippert ${ }^{1,4}$ \\ ${ }^{1}$ Laboratory for Multiscale Materials Experiments, Paul Scherrer Institute, 5232 Villigen PSI, Switzerland \\ ${ }^{2}$ Ion Beam Physics, ETH Zurich, 8093 Zurich, Switzerland \\ ${ }^{3}$ Center for Electronic Correlations and Magnetism, University of Augsburg, 86135 Augsburg, Germany \\ ${ }^{4}$ Department of Chemistry and Applied Biosciences, Laboratory of Inorganic Chemistry, ETH Zurich, Switzerland
}

(Received 23 July 2019; revised manuscript received 18 November 2019; published 23 December 2019)

\begin{abstract}
$\mathrm{SrTiO}_{3}$ thin films were grown on ${ }^{18} \mathrm{O}$-exchanged $\mathrm{SrTiO}_{3}$ single crystalline substrates by pulsed-laser deposition, rf sputtering, and oxide molecular-beam epitaxy to study their oxygen diffusion depth profiles using secondary ion mass spectrometry and elastic recoil detection analysis depth profiling. The oxygen depth profiling shows that $\mathrm{SrTiO}_{3}$ films prepared with the three different deposition techniques will take oxygen from the substrate, even at room temperature. This confirms that the substrate is one possible oxygen source for the growth of oxide thin films independent of the physical vapor deposition technique employed. It was also found that a reactive oxygen environment changes the oxygen composition of the substrate during the growth of a film and partly replaces ${ }^{18} \mathrm{O}$ with ${ }^{16} \mathrm{O}$ up to a depth of several tens of nm. These findings imply that $\mathrm{SrTiO}_{3}$ and therefore other ion conducting oxide substrates, which are commonly used as platforms for thin film growth, can be considered capricious in nature with respect to oxygen chemistry and lattice constants.
\end{abstract}

DOI: 10.1103/PhysRevMaterials.3.123401

\section{INTRODUCTION}

Physical vapor deposition (PVD) techniques are commonly used to deposit metals and oxides as thin films where atoms, molecules, and clusters are directly transported from a source or a solid target to the substrate through a gas or a plasma phase. These sources provide the thermal energy to release the species into the vapor phase as occurs in thermal or electron beam evaporation, e.g., molecular beam evaporation (MBE). Alternatively, material can be removed physically from a solid target such as using the incident energy of accelerated charged particles (sputtering) or the intense light field of a laser [pulsed-laser deposition (PLD)]. Characteristic for each of the deposition techniques is the pressure range defining to some extend the growth properties, chemistry, and physical properties of a material. MBE is operated at a very low vacuum $\left(<10^{-6} \mathrm{mbar}\right)$, sputtering between $10^{-3}$ and $1 \mathrm{mbar}$, and PLD at any pressure below $\approx 1$ mbar. The advantage of PLD over the other PVD techniques is the flexibility to deposit almost any material as thin film with a complex composition [1-3].

A recent example where all three oxide deposition techniques (PLD [4-6], sputtering [7-9], MBE [10]) have been successfully employed is the $\mathrm{LaAlO}_{3}-\mathrm{SrTiO}_{3}$ system resulting in conducting interfaces which can become superconducting [11] and magnetic [12]. Another example is homoepitaxially grown $\mathrm{SrTiO}_{3}$ [13-23]. The interest to understand the growth of $\mathrm{SrTiO}_{3}$ is based on the versatile properties of the materials itself. The very large dielectric constant is of interest to utilize $\mathrm{SrTiO}_{3}$ as a crystalline gate dielectric in, e.g., siliconbased field-effect devices [24]. Photocatalytic water-splitting [25], or strain induced ferroelectricity when grown as a thin film [26] are also technologically relevant properties that

\footnotetext{
*Corresponding author: Christof.Schneider@psi.ch
}

require a precise composition control (usually the cations), which also affects the surface structure at the atomic scale $[21,27]$. In addition to the cation composition of $\mathrm{SrTiO}_{3}$, it is important to also adjust the oxygen content, which is vital, since the overall composition will determine the physical properties [28]. When growing $\mathrm{SrTiO}_{3}$ homoepitaxially a key question is the source of the oxygen: Background gas, the target, or the substrate [15,29-31]. An unknown quantity is how much the oxygen composition depends on the growth technique and how the main oxide deposition techniques (PLD, sputtering, MBE) compare. If there are deposition related differences, does this depend on growth conditions specific to the growth technique employed (substrate temperature, oxidant pressure)? Equally important is the kind of reactive atmosphere and vapor phase (plasma) condition as in the presence of negative oxygen ions or atomic oxygen [16,32].

Potential sources for the oxygen supplied during thin film growth by PLD are the background gas, the target [29] and the substrate [30]. By selecting two of the sources, target and substrate, and selectively isotope substitute ${ }^{16} \mathrm{O}_{2}$ with ${ }^{18} \mathrm{O}_{2}$, it is possible to distinguish the contribution of the background gas to the growth of a film. For a low-pressure deposition, the main oxygen source for the film is the target whereas almost all oxygen in a film originates from the background gas if the deposition is done in the $10^{-1} \mathrm{mbar}$ range [29]. The role of the substrate as an oxygen source for a film was studied in the context of growing $\mathrm{LaAlO}_{3}$ and $\mathrm{SrTiO}_{3}$ thin films at different deposition temperatures by PLD [30]. Both, $\mathrm{LaAlO}_{3}$ and $\mathrm{SrTiO}_{3}$ films take oxygen from the substrate at any of the deposition temperatures. These experiments showed that the substrate is a potential oxygen source for a film during growth.

To generalize the context of oxygen for the growth of $\mathrm{LaAlO}_{3}$ thin films on $\mathrm{SrTiO}_{3}$ substrates [30] we study the 
TABLE I. Summary of the main properties of pulsed laser deposition, $\mathrm{rf}$ sputtering and oxide MBE, and the deposition parameters for the $\mathrm{SrTiO}_{3}$ thin film growth.

\begin{tabular}{|c|c|c|c|}
\hline & PLD & Sputtering & Oxide MBE \\
\hline Target/Source & Solid & Solid & Metal \\
\hline Energy for material removal & $\begin{array}{l}\text { Photons, } \lambda=248 \mathrm{~nm} \\
20 \mathrm{nsec} \text { pulse }\end{array}$ & Electrical discharge & $\begin{array}{l}\text { Thermal evaporation, } \\
\text { sublimation }\end{array}$ \\
\hline Depos. pressure (mbar) & $1,5 \times 10^{-5}$ & $5 \times 10^{-3}$ & $6.7 \times 10^{-6}$ \\
\hline Mean free path $(\mathrm{cm})$ & $\approx 450$ & $\approx 1.5$ & $\approx 1000$ \\
\hline Background gas & $\mathrm{O}_{2}$ & $\mathrm{O}_{2}$ & $\mathrm{O}_{2}$ and $\mathrm{O}_{2}+\mathrm{O}_{3}$ \\
\hline Deposition Temp. $\left({ }^{\circ} \mathrm{C}\right)$ & RT, 650, and 750 & RT, 650, and 750 & RT, 650,750, and 850 \\
\hline Kinetic Energy (eV) & $\begin{array}{l}\text { Large fraction of species with } \\
E_{\text {kin }} \approx 2-5 E_{\text {kin,max }} \\
\text { up to several } 100 \mathrm{eVs}\end{array}$ & $\begin{array}{l}\text { Large fraction of species with } \\
\qquad E_{\mathrm{kin}} \approx 2-10\end{array}$ & $E_{\text {kin }}: 0.1-0.2$ \\
\hline Comments & $\begin{array}{l}\text { Plasma: neutral, ions mostly } \\
\text { ground state and excited } \\
\text { atomic and di-atomic species }\end{array}$ & $\begin{array}{l}\text { Plasma: neutral, ions mostly } \\
\text { ground state and excited } \\
\text { atomic species }\end{array}$ & $\begin{array}{l}\text { Cloud of neutral species } \\
\text { with a low } E_{\text {kin }}\end{array}$ \\
\hline
\end{tabular}

oxygen depth profiles of $\mathrm{SrTiO}_{3}$ thin films grown on ${ }^{18} \mathrm{O}$ enriched $\mathrm{SrTiO}_{3}$ single crystalline substrates using secondary ion mass spectrometry (SIMS) and elastic recoil detection analysis (ERDA) depth profiling. Both techniques provide reliable depth profiles of the ${ }^{18} \mathrm{O} /{ }^{16} \mathrm{O}$ ratio and give insight on how the enriched isotope spreads from the substrate into the film during growth. The $\mathrm{SrTiO}_{3}$ films were grown by PLD at three different deposition temperatures to investigate the respective changes in depth profiles. To understand whether the oxygen diffusion behavior is intrinsic or limited to ablated films, $\mathrm{SrTiO}_{3}$ films have also been prepared by rf sputtering and MBE. We show that oxygen from the background as well as from the substrate is incorporated into the films during growth. In addition, oxygen from the background can also change the oxygen balance in the substrate during the growth of the film.

\section{EXPERIMENTAL METHODS}

To study the oxygen diffusion into thin films supplied via the substrate, $\mathrm{SrTiO}_{3}$ films were grown by PLD, rf sputtering, and oxide MBE on ${ }^{18} \mathrm{O}$ isotope exchanged (100) $\mathrm{SrTiO}_{3}$ single crystalline substrates. These techniques where selected because PLD growth can be conducted over a large pressure range and is based on the transfer of ionic and neutral species (metallic as well as metal-oxygen species) in the ground and excited state, here at a low oxygen pressure of $10^{-5} \mathrm{mbar}$, with a high kinetic energy from the target to the substrate. Sputtering, like PLD, is a plasma-based technique and depends on a reactive background atmosphere (oxygen) to prepare oxide thin films. MBE is a very low-pressure technique $\left(<10^{-6}\right.$ mbar $)$ utilizing thermal effusion cells or electronbeam evaporators and having next to the growing film a local reactive environment either using oxygen or oxygen plus ozone to prepare oxide films. For a better comparison of the different deposition techniques their main properties are summarized in Table I. After film growth, the oxygen depth profile was established by dynamic secondary ion mass spectrometry (D-SIMS) and ERDA.

When discussing growth temperatures, different growth systems measure substrate temperatures in different ways and pressures at different positions. Even at nominally identical deposition temperatures the actual temperature of the substrate surface may differ substantially between different deposition chambers. For our experiments, the temperature for sputtering and PLD is measured using a pyrometer on the heater next to the substrate while for MBE a thermocouple is used. Since the type of heater for each system is different, and likewise the coupling of the film to the heat source, only the nominal temperature as determined for each deposition system is mentioned.

\section{A. Pulsed laser deposition}

$\mathrm{SrTiO}_{3}$ thin films prepared by PLD have been grown at three different deposition temperatures, $T_{\mathrm{S}}$ : nominal room temperature, $650^{\circ} \mathrm{C}$, and $750^{\circ} \mathrm{C}$, a typical temperature range to grow $\mathrm{SrTiO}_{3}$. The laser wavelength was $\lambda=248 \mathrm{~nm}$ and the laser repetition frequency $10 \mathrm{~Hz}$. The oxygen background pressure was $p=1.5 \times 10^{-5}$ mbar with a fluence $F=4 \mathrm{~J} \mathrm{~cm}^{-2}$ from a sintered rod-target with resulting film thicknesses of $\approx 60 \mathrm{~nm}$. After deposition the films were cooled down to room temperature in the same oxygen background pressure $\left(1.5 \times 10^{-5} \mathrm{mbar}\right)$ in which they were grown, i.e., without in situ oxygen annealing. Films deposited at room temperature are typically amorphous whereas epitaxial films were grown with a $(001)$ orientation at $650^{\circ} \mathrm{C}$ and $750^{\circ} \mathrm{C}$. The composition of these films was measured using Rutherford back scattering (RBS) [33] and ERDA [34] yielding an average composition of $\mathrm{Sr}_{0.97} \mathrm{Ti}_{1.03} \mathrm{O}_{2.52}$ when grown at $750{ }^{\circ} \mathrm{C}$ [30]. The composition of films grown at other temperatures where not measured. These $\mathrm{SrTiO}_{3}$ films had a bluish colour and were electrically conducting, as expected from oxygen deficient $\mathrm{SrTiO}_{3}$ films.

\section{B. RF sputtering}

The $\mathrm{SrTiO}_{3}$ thin films grown by sputtering were deposited at room temperature, $650{ }^{\circ} \mathrm{C}$, and $750{ }^{\circ} \mathrm{C}$ from a sintered $\mathrm{SrTiO}_{3}$ target (5-cm diameter) in an 1:1 Ar:O $\mathrm{O}_{2}$ atmosphere with an $\mathrm{rf}$ power of $P=40 \mathrm{~W}$ and a total pressure of $p=$ $5 \times 10^{-3}$ mbar yielding a film thickness of $\approx 25 \mathrm{~nm}$ for each film. After the deposition, the heater was switched off and 
the films cooled down to room temperature in the deposition atmosphere. All films were transparent, insulating, and the film thickness was verified using $\mathrm{x}$-ray reflectometry. No composition analysis was done. Due to the highly insulating nature of these films, it is assumed that the oxygen content is very close to $\mathrm{SrTiO}_{3.0}$.

\section{Oxide MBE}

The growth of $\mathrm{SrTiO}_{3}$ films by oxide MBE was performed at $100,650,750$, and $875^{\circ} \mathrm{C}$ in a background pressure of $p=$ $6.7 \times 10^{-6}$ mbar of $\mathrm{O}_{2}$ or $\left(\mathrm{O}_{2}: \mathrm{O}_{3}\right)$ as described in Ref. [16], respectively, to provide a different reactive environment. The layer-by-layer growth was monitored using reflection highenergy electron diffraction, and films with a thickness of $\approx 40 \mathrm{~nm}$ when grown at a high temperature, and $\approx 100 \mathrm{~nm}$ at room temperature, were obtained. From the value of the out-of-plane lattice parameter measured by x-ray diffraction, the film composition was stoichiometric within the $\sim 1 \%$ resolution of this assessment [16]. All films grown at high temperatures were transparent and insulating, and no additional composition analysis was done. Due to the highly insulating nature of these films, it is assumed that the oxygen content is very close to $\mathrm{SrTiO}_{3.0}$.

\section{RBS and ERDA}

RBS and ERDA are two nuclear, nondestructive scattering techniques to determine the composition and elemental depth profile of thin films. RBS measurements were performed using a $2-\mathrm{MeV}{ }^{4} \mathrm{He}$ ion beam and a silicon surface barrier detector at a scattering angle of $168^{\circ}$. The collected RBS data were simulated with the RUMP software [35]. The experimental uncertainty (accuracy) in cations and oxygen stoichiometries as determined by RBS, are $\pm 3 \%$ and $\pm 5 \%$, respectively. The oxygen content in the films was calculated from the combination of RBS results and the measured ${ }^{16 / 18} \mathrm{O}$ concentration ratios obtained from ERDA. For the ERDA measurements a $13-\mathrm{MeV}{ }^{127} \mathrm{I}$ beam was used under an $18^{\circ}$ incident and exit angle. The scattered recoils were identified by the combination of a time-of-flight spectrometer with a gas ionization chamber. The experimental uncertainty in determining the ${ }^{16 / 18} \mathrm{O}$ ratio is about $\pm 5 \%$. From ERDA, we also obtain ${ }^{18} \mathrm{O}$ depth profiles. The resolution limit of the depth profile results from multiple small angle scatterings of incident and recoiling ions by atoms of the film. It is significantly degraded if heavy recoil atoms are involved and is estimated to be at least $15 \mathrm{~nm}$ for the presented experiments. Also, the information depth of the presented ERDA data is between 60 and $70 \mathrm{~nm}$ into the substrate. For consistency, RBS and ERDA measurements have also been conducted on single crystalline $\mathrm{SrTiO}_{3}$ substrates where the uncertainty in the composition $(\mathrm{Ti}=1, \mathrm{Sr}=0.99 \pm 0.01, \mathrm{O}=2.99 \pm$ $0.06)$ is purely statistical.

\section{E. Dynamic SIMS}

Like RBS and ERDA, depth resolved mass spectrometry is used to determine the composition and elemental depth profiles of a sample. For D-SIMS a quadrupole mass spectrometer (Hiden analytical EQS) is operated at a residual background pressure of $<10^{-7}$ mbar with a 2.5 - and $1.7-\mathrm{keV}$ Ar ion beam focused to a spot of $150-\mu \mathrm{m}$ diameter. All depth profiles for PLD-grown $\mathrm{SrTiO}_{3}$ films were measured using $2.5 \mathrm{keV}$; Sputtered and MBE-grown $\mathrm{SrTiO}_{3}$ films have been profiled using a 1.7-keV Ar ion beam. The latter step was done to improve the depth resolution of the thin films by reducing the intermixing of atoms during ion sputtering. For our experimental setup a depth resolution of $\approx 5 \mathrm{~nm}$ is achieved as determined from measuring a $\mathrm{YBa}_{2} \mathrm{Cu}_{3} \mathrm{O}_{7} / \mathrm{La}_{0.66} \mathrm{Ca}_{0.33} \mathrm{MnO}_{3}$ multilayer with a $10-\mathrm{nm} / 10-\mathrm{nm}$ layer sequence. The ion beam current is monitored by a Faraday cup and the rastering of the ion beam takes place over a square of $1 \times 1 \mathrm{~mm}$ with an effective sampling area of $500 \times 500 \mu \mathrm{m}^{2}$ in the center of the sputtered square to analyze only the ions from a "flat" area. After ion etching, the depth of the etched area is measured with a Dektak 8 profilometer and a mapping between etching time and depth is established. In addition, an electron flood gun was used to compensate excess charges due to the ion etching on insulating substrates. Occasionally, the surface properties changed gradually during measurements and the initially optimized charge compensation was offset, leading to a constant change in the measured intensities with increasing measurement time. This was particularly noticeable when measuring into the substrate. In this case a constant background has been subtracted from the measured data. Typically, the etching depth into the substrate was between 150 and $250 \mathrm{~nm}$ to ensure to measure a constant ${ }^{18} \mathrm{O}$ intensity, indicating a homogeneous oxygen content. This flat depth profile is used as a reference by assuming that the oxygen composition of the substrate is $\mathrm{SrTiO}_{3.0}$. The depth dependence of, at most, four elements $\left({ }^{16} \mathrm{O}^{-},{ }^{18} \mathrm{O}^{-}, \mathrm{Sr}^{+}, \mathrm{Ti}^{+}\right)$ has been recorded to keep the balance between sufficient depth resolution and time required to record the intensities of the different elements. To discriminate ${ }^{18} \mathrm{O}$ from $\mathrm{H}_{2}{ }^{16} \mathrm{O}$ a kinetic energy selection was done [36]. To calculate the ${ }^{18} \mathrm{O}$ concentration, labeled "Normalized Intensity" in the figures, the measured ${ }^{18} \mathrm{O}$ intensity was divided by the sum of the ${ }^{16} \mathrm{O}$ and ${ }^{18} \mathrm{O}$ intensities $\left[{ }^{18} \mathrm{O} /\left({ }^{16} \mathrm{O}+{ }^{18} \mathrm{O}\right)\right]$.

\section{F. Isotope exchange}

The ${ }^{18} \mathrm{O}$ exchange involving $\mathrm{SrTiO}_{3}$ was conducted at various temperatures in $91 \%$ isotopically pure ${ }^{18} \mathrm{O}$ with the aim to enrich the near-surface region of the substrates with ${ }^{18} \mathrm{O}$ as much as possible. $\mathrm{SrTiO}_{3}$ substrates [18] were exchanged at 1000 and $1100{ }^{\circ} \mathrm{C}$ for one week each to reach a bulk exchanged content of $\approx 71 \%$ and $\approx 90 \%$, respectively. This corresponds to $\approx 85 \%{ }^{18} \mathrm{O}$ at the near-surface region when the annealing took place at $1000{ }^{\circ} \mathrm{C}$. For these substrates, the isotope exchange took place within a thickness of up to $100 \mu \mathrm{m}$ as verified by lapping an exchanged substrate and using Raman microscopy [37]. Likewise, $\mathrm{SrTiO}_{3}$ substrates exchanged at $900{ }^{\circ} \mathrm{C}$ for $12 \mathrm{~h}$ reached an equilibriums concentration of $36 \%{ }^{18} \mathrm{O}$, and the surface ${ }^{18} \mathrm{O}$ concentration varied between 70 and $80 \%$ as determined by ERDA and SIMS. The surface-near ${ }^{18} \mathrm{O}$ concentration of $\mathrm{SrTiO}_{3}(1-3 \mu \mathrm{m})$ has been confirmed using confocal Raman microscopy by measuring the isotope induced shift of the Raman active mode at $683 \mathrm{~cm}^{-1}$ for nonexchanged $\mathrm{SrTiO}_{3}$. A $100 \%{ }^{18} \mathrm{O}$ exchange would shift this mode from $683 \mathrm{~cm}^{-1}$ to $645.8 \mathrm{~cm}^{-1}$. Since 
the maximum surface concentration cannot be larger than the concentration of the exchange gas, the maximum shift was $649.5 \mathrm{~cm}^{-1}$ as experimentally confirmed when using a $100 \mathrm{x}$ objective probing a volume of $\approx 1 \mu \mathrm{m}^{3}$. To correct for potential offsets in the as-measured $\mathrm{SrTiO}_{3}$ spectrum we used the Raman active mode of $\mathrm{Si}$ at $\approx 520 \mathrm{~cm}^{-1}$ as a reference. We do not distinguish between different $\mathrm{SrTiO}_{3}$ chemical surface terminations since the very long annealing time to reach a high surface-near ${ }^{18} \mathrm{O}$ concentration will offset a correct $\mathrm{TiO}_{2}$ termination. A shorter annealing time can still be done when studying properties related to a properly terminated interface albeit with a much reduced ${ }^{18} \mathrm{O}$ near-surface and a very small bulk concentration.

\section{RESULTS AND DISCUSSION}

When growing an oxide thin film, the oxygen incorporation happens in multiple stages. First during film growth and second during cooling after growth. If a film is cooled in vacuum, it can lose oxygen. If a film is cooled at the same pressure in which it was grown, it can gain oxygen. In order to discriminate the potential origin of the oxygen source (background, target [29,31] or substrate [30]) growth experiments using the ${ }^{18} \mathrm{O}$ isotope as a trace element are required and the final oxygen profile in a film plus substrate can be measured using SIMS and ERDA. Dislocations are not a pathway for oxygen when discussing oxygen diffusion in $\mathrm{SrTiO}_{3}$ single crystals and films [38]. They are blocking the oxygen diffusion rather than supporting it [39-42].

For the following discussion on ${ }^{18} \mathrm{O}$ depth profiles, we will first concentrate on the substrate as a reference point to distinguish under which deposition conditions a film takes or loses oxygen and if this is deposition technique specific. Next, we present SIMS and ERDA thin film data for PLD grown films. For the ${ }^{18} \mathrm{O}$ depth profiling of sputtered and MBE grown films, only SIMS measurements are done due to the much better depth resolution as compared to ERDA.

\section{A. ${ }^{18} \mathrm{O}$ exchanged substrates}

Starting with the substrate, the redistribution of ${ }^{18} \mathrm{O}$ happens in multiple stages. Upon heating of the substrate to growth temperature, an ${ }^{18} \mathrm{O}$ exchange could take place with the ambient gas $\left({ }^{16} \mathrm{O}\right)$ even before growth begins. For in situ strain measurements using $\mathrm{SrTiO}_{3}$ as the growth template, a stable signal to monitor strain in a growing film cannot be achieved at elevated temperatures because oxygen diffusion is causing a strongly fluctuating and drifting signal [43]. This implies that a substrate like $\mathrm{SrTiO}_{3}$ can be considered capricious in nature in terms of chemistry for film growth. A growing $\mathrm{SrTiO}_{3}$ film could obtain ${ }^{18} \mathrm{O}$ from the substrate during growth. Even if the growing film does not take ${ }^{18} \mathrm{O}$ from the substrate during growth [29], it could exchange the oxygen obtained from the gas phase $\left({ }^{16} \mathrm{O}\right)$ with oxygen from the substrate $\left({ }^{18} \mathrm{O}\right)$ due to postgrowth interdiffusion.

\section{B. Comparison of ERDA and SIMS depth profiles}

The ERDA and SIMS ${ }^{18} \mathrm{O}$ depth profiles of three PLDgrown $\mathrm{SrTiO}_{3}$ films are shown in Fig. 1. As is evident from Fig. 1, the ${ }^{18} \mathrm{O}$ depth profiles for the films grown at the three
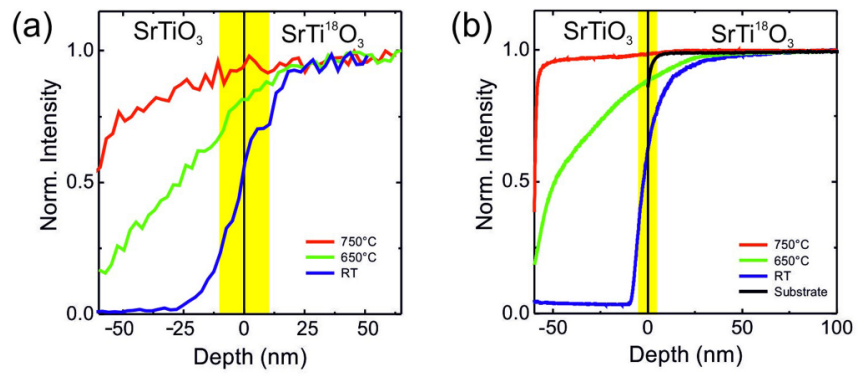

FIG. 1. Normalized ${ }^{18} \mathrm{O}$ depth profiles of $\approx 60 \mathrm{~nm}$ thick $\mathrm{SrTiO}_{3}$ thin films grown at $p=1.5 \times 10^{-5}$ mbar using PLD on ${ }^{18} \mathrm{O}$ exchanged $\mathrm{SrTiO}_{3}$ substrates at three different temperatures: room temperature (blue), $650{ }^{\circ} \mathrm{C}$ (green), and $750{ }^{\circ} \mathrm{C}$ (red). The depth profiles have been measured with (a) ERDA and (b) SIMS [30]. For comparison, a depth profile of a bare ${ }^{18} \mathrm{O}$ exchanged substrate is shown (black). The yellow bar indicates the nominal width of the film-substrate interface as obtained from the depth resolution. Data from Ref. [30] have been reanalyzed and redrawn.

different $T_{\mathrm{S}}$ changes dramatically. As a reference the SIMS depth profile of a bare ${ }^{18} \mathrm{O}$ exchanged substrate has been measured [Fig. 1(b)]. The ${ }^{18} \mathrm{O}$ signal is almost constant up to the surface with a small decrease of the signal towards the substrate surface. The sharp increase of the ${ }^{18} \mathrm{O}$ SIMS signal at the substrate surface is related to the finite resolution of the SIMS setup and the initial sputtering process giving rise to nonphysical results. We therefore neglect the signal measured for the initial $5 \mathrm{~nm}$ when discussing properties but show the full measurement for completeness.

Comparing substrate and $\mathrm{SrTiO}_{3}$ film data deposited at room temperature, we note that already at room temperature oxygen is removed during the deposition from the substrate up to a depth of 50 to $100 \mathrm{~nm}$. At $T_{\mathrm{S}}=650^{\circ} \mathrm{C}$, both ERDA and SIMS show a substantial ${ }^{18} \mathrm{O}$ migration from the substrate into the film [30]. In contrast, at $T_{\mathrm{S}}=750{ }^{\circ} \mathrm{C}$ the amount of ${ }^{18} \mathrm{O}$ measured in the film and substrate is almost constant with a small decrease of the signal towards the film surface when traced using SIMS. The ERDA depth profile also shows a decrease of the ${ }^{18} \mathrm{O}$ signal towards the film surface, but more pronounced compared to the SIMS measurement. These two independent measurements therefore confirm that the $\mathrm{SrTiO}_{3}$ substrate is indeed supplying oxygen to $\mathrm{SrTiO}_{3}$ films during growth [30]. SIMS depth profiles for $\mathrm{Sr}$ and $\mathrm{Ti}$ were simultaneously collected with the ${ }^{18} \mathrm{O}^{-}$and ${ }^{16} \mathrm{O}^{-}$ions. The $\mathrm{Sr}$ and $\mathrm{Ti}$ concentrations are the same within the experimental uncertainty for the film and the substrate. This allows us to exclude matrix effects, preferential sputtering, or knock-on artefacts and conclude that oxygen in the $\mathrm{SrTiO}_{3}$ film is supplied by the substrate. Oxygen exchange with the substrate was also observed when depositing $\mathrm{SrTiO}_{3}$ on ${ }^{18} \mathrm{O}$ exchanged $\mathrm{LaAlO}_{3}$ substrates [30].

\section{Oxygen diffusion at the film-substrate interface}

To study the oxygen diffusion from the substrate into a film in more detail, we compare the ${ }^{18} \mathrm{O}$ and ${ }^{16} \mathrm{O}$ SIMS profiles of $\mathrm{SrTiO}_{3}$ films grown at $T_{\mathrm{S}}=750$ and $650{ }^{\circ} \mathrm{C}$ on $90 \%{ }^{18} \mathrm{O}$-exchanged $\mathrm{SrTiO}_{3}$ substrates (Fig. 2). The measured intensities for ${ }^{18} \mathrm{O}$ and ${ }^{16} \mathrm{O}$ have been normalized with respect 

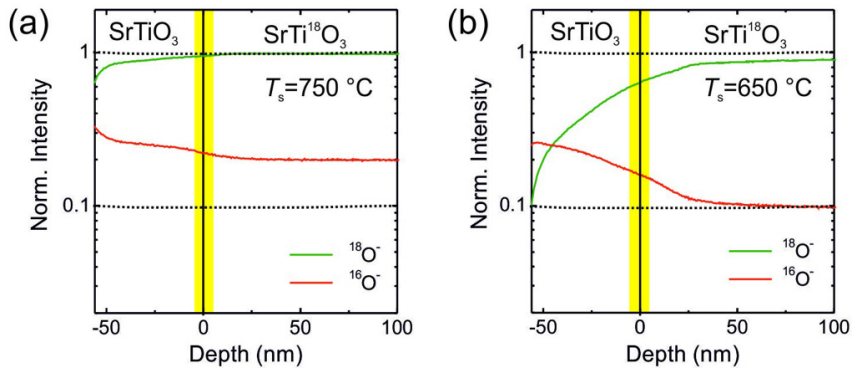

FIG. $2 .{ }^{18} \mathrm{O}$ and ${ }^{16} \mathrm{O}$ SIMS depth profiles of $\approx 60$-nm-thick $\mathrm{SrTiO}_{3}$ thin films grown at (a) $750{ }^{\circ} \mathrm{C}$ and (b) at $650{ }^{\circ} \mathrm{C}$ on ${ }^{18} \mathrm{O}$ exchanged $\mathrm{SrTiO}_{3}$. The yellow bar indicates the nominal width of the film substrate interface. The dotted lines correspond to the normalized ${ }^{16} \mathrm{O}$ and ${ }^{18} \mathrm{O}$ concentration in the surface near volume of the ${ }^{18 / 16} \mathrm{O}$-exchanged $\mathrm{SrTiO}_{3}$ substrate.

to the maximum ${ }^{18} \mathrm{O}$ intensity collected from the depth of the substrate. For the $\mathrm{SrTiO}_{3}$ film grown at $T_{\mathrm{S}}=750^{\circ} \mathrm{C}$ [Fig. 2(a)], the ${ }^{18} \mathrm{O}$ signal in the substrate stays almost constant up to the film-substrate interface before a drop of the signal towards the film surface takes place. The ${ }^{16} \mathrm{O}$ depth profile seems to be almost complementary with respect to ${ }^{18} \mathrm{O}$. The enhanced signal in the film decreases from the film surface towards the film-substrate interface and stays constant in the substrate. The intensity ratio for ${ }^{18} \mathrm{O}$ and ${ }^{16} \mathrm{O}$ in the substrate shows that approximately $80 \%$ of ${ }^{16} \mathrm{O}$ has been exchanged in this near-surface volume with ${ }^{18} \mathrm{O}$, which is in agreement with ERDA measurements. Also, the increase in the ${ }^{16} \mathrm{O}$ intensity in the film proves that some oxygen $\left({ }^{16} \mathrm{O}\right)$ is supplied during the growth from the target or gas ambient. The expected ${ }^{16} \mathrm{O}$ signal in the substrate should be approximately $10 \%$ of the ${ }^{18} \mathrm{O}$ signal (dashed line in Fig. 2), which is clearly not the case. One possible explanation is that the vacuum deposited $\mathrm{SrTiO}_{3-x}$ film is initially more oxygen deficient than the RBS-determined composition of $\mathrm{Sr}_{0.97} \mathrm{Ti}_{1.03} \mathrm{O}_{2.52}$ and the oxygen deficiency is partly compensated by taking oxygen from the substrate. As pointed out, the film/substrate system has a blueish colour and is electrically conducting, which means that sufficient oxygen vacancies in the substrate have been created. An indication is the level of the ${ }^{16} \mathrm{O}$ signal significantly larger than the nominal 10\% limit and reaching much deeper into the substrate than the typical sputtering depth to track the signal. The ${ }^{16} \mathrm{O}$ must therefore originate from the bulk of the substrate since the target does not provide enough extra oxygen to explain the enhanced level for the ${ }^{16} \mathrm{O}$ signal in the substrate.

For the $\mathrm{SrTiO}_{3}$ film grown at $T_{\mathrm{S}}=650^{\circ} \mathrm{C}$ [Fig. 2(b)], the decrease of the ${ }^{18} \mathrm{O}$ signal from the substrate into the film is much more pronounced compared to the film grown at $T_{\mathrm{S}}=$ $750{ }^{\circ} \mathrm{C}$ and the point at which the ${ }^{18} \mathrm{O}$ signal reaches saturation in the substrate is deeper than the 250-nm depth measured by SIMS (not shown). The ${ }^{16} \mathrm{O}$ signal in the substrate is approximately $10 \%$ of the ${ }^{18} \mathrm{O}$ signal, and increases strongly near the substrate-film interface into the film. Like for the growth at $T_{\mathrm{S}}=750{ }^{\circ} \mathrm{C}$, some ${ }^{16} \mathrm{O}$ is supplied from the target or gas ambient and the diffusion of ${ }^{18} \mathrm{O}$ from the depth of the $\mathrm{SrTiO}_{3}$ substrate during the growth takes place on a time scale of minutes, the deposition time for growing the film. This is shown by the shallow gradient deep into the substrate and the significant decrease in the ${ }^{18} \mathrm{O}$ intensity starting $\approx 25 \mathrm{~nm}$ away from the substrate-film interface. When measuring an ${ }^{18} \mathrm{O}$ exchanged $\mathrm{SrTiO}_{3}$ substrate only, the ${ }^{18} \mathrm{O}$ intensity respective depth profile is flat except for the first few $\mathrm{nm}$ at the substrate surface [see Fig. 1(b)].

\section{Oxygen profiles for sputtered and oxide MBE grown films}

So far, the oxygen depth profiles for PLD grown films have been analyzed. Sputtering and oxide MBE are the other main deposition techniques to grow high-quality oxide thin films. The question is, how do oxygen profiles of $\mathrm{SrTiO}_{3}$ films prepared with these physical vapor deposition techniques compare to PLD-grown films? To investigate this question, three different sets of $\mathrm{SrTiO}_{3}$ films were fabricated on ${ }^{18} \mathrm{O}$-exchanged $\mathrm{SrTiO}_{3}$ substrates using sputtering and oxide MBE.

For sputtered films, the SIMS ${ }^{18} \mathrm{O}$ depth profile of the film grown at room temperature is similar to films prepared using PLD at the nominal same $T_{\mathrm{S}}$ [Fig. 3(a)]. The depth profile of the film grown at $T_{\mathrm{S}}=650^{\circ} \mathrm{C}$ shows an almost flat distribution whereas the film grown at $T_{\mathrm{S}}=750^{\circ} \mathrm{C}$ shows slightly less ${ }^{18} \mathrm{O}$ in the film compared to the films grown at $T_{\mathrm{S}}=650{ }^{\circ} \mathrm{C}$. Even in the $\mathrm{SrTiO}_{3}$ substrate the ${ }^{18} \mathrm{O}$ concentration of the film grown at $T_{\mathrm{S}}=750^{\circ} \mathrm{C}$ appears to be reduced up to depth of several tens of $\mathrm{nm}$. Since the ${ }^{18} \mathrm{O}$ profile of the film grown at $T_{\mathrm{S}}=650^{\circ} \mathrm{C}$ is flat with a concentration almost like the substrate, a reduction of ${ }^{18} \mathrm{O}$ at $T_{\mathrm{S}}=750{ }^{\circ} \mathrm{C}$ suggest that there is an oxygen diffusion of the ${ }^{16} \mathrm{O}$ background into the film and substrate. This diffusion behavior at different $T_{\mathrm{S}}$ is not observed for PLD and most likely due to the lower oxygen background pressure used for PLD $\left(10^{-3} \mathrm{mbar}\right.$ vs $\left.10^{-5} \mathrm{mbar}\right)$.

The second and third set of $\mathrm{SrTiO}_{3}$ films were prepared by oxide MBE with an $\mathrm{O}_{2}$ background [Fig. 3(b)] with one set being grown in the presence of ozone [Fig. 3(c)]. In addition to the three deposition temperatures utilized for the growth of the films by PLD and sputtering, one film was prepared at $T_{\mathrm{S}}=$ $875^{\circ} \mathrm{C}$ to enhance the oxygen mobility of the substrate for the homoepitaxial growth of $\mathrm{SrTiO}_{3}$. As the depth profiles of the $\mathrm{SrTiO}_{3}$ films grown in $\mathrm{O}_{2}$ at high deposition temperatures show, all films acquire oxygen $\left({ }^{18} \mathrm{O}\right)$ from the substrate similar to PLD-grown films [Fig. 3(b)]. In the case of the $\mathrm{SrTiO}_{3}$ films grown in the ozone atmosphere [Fig. 3(c)] less ${ }^{18} \mathrm{O}$ is found in the $\mathrm{SrTiO}_{3}$ films as compared to the films grown in $\mathrm{O}_{2}$ at the same deposition temperature [Fig. 3(b)]. This suggests, that $\mathrm{SrTiO}_{3}$ grown in the more reactive atmosphere takes less oxygen from the substrate since readily available, active oxygen is provided by the background gas to form an insulating, and hence, a fully stoichiometric film [16].

When comparing all four $\mathrm{SrTiO}_{3}$ films grown at $T_{\mathrm{S}}=$ $750{ }^{\circ} \mathrm{C}$ [Fig. 4(a)], we note an ${ }^{18} \mathrm{O}$ depletion of the substrate surface region for sputtering and MBE using ozone. This indicates that a more reactive oxygen environment changes the oxygen composition of the substrate during the growth and partly replaces ${ }^{18} \mathrm{O}$ with ${ }^{16} \mathrm{O}$ up to a depth of several tens of $\mathrm{nm}$. As noted, the ${ }^{18} \mathrm{O}$ signal at a depth of 150 to $250 \mathrm{~nm}$ in the substrate was typically constant. Observing the exchange of ${ }^{16} \mathrm{O}$ and ${ }^{18} \mathrm{O}$ even in the substrate also indicates that the ${ }^{18} \mathrm{O}$ supplied from the bulk to the substrate surface 

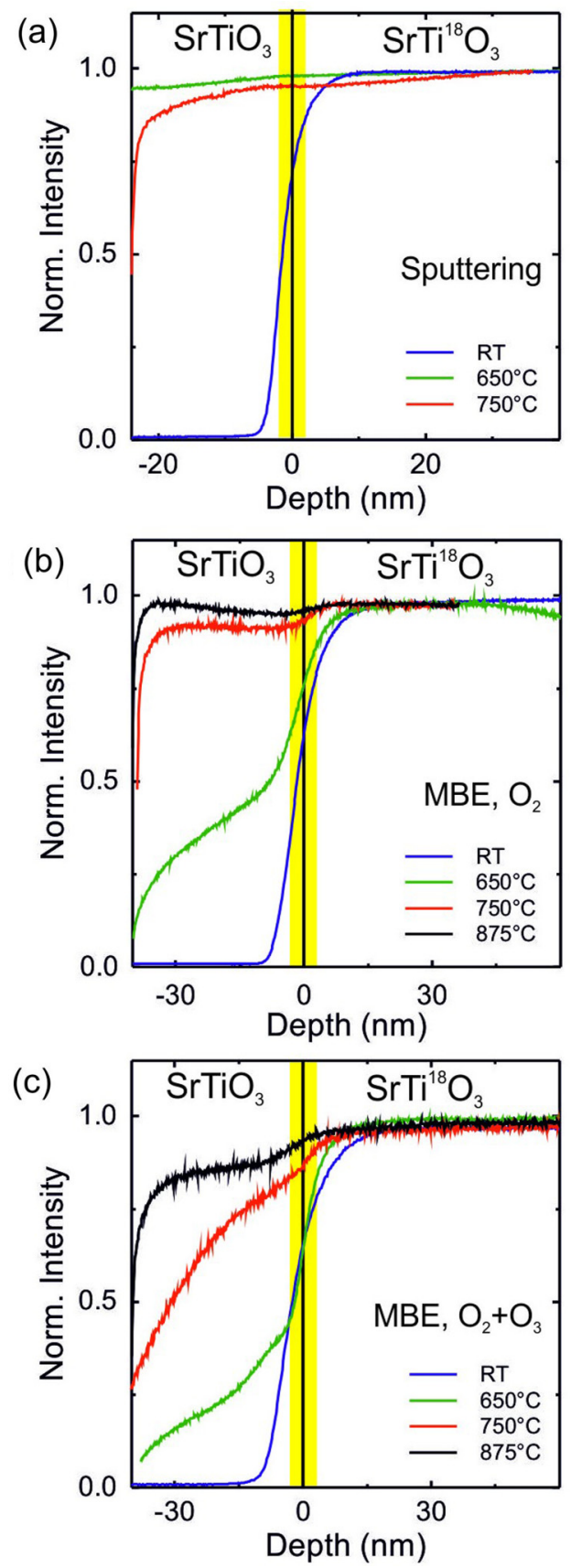

FIG. 3. (a) ${ }^{18} \mathrm{O}$ SIMS depth profiles of $\approx 25$-nm-thick $\mathrm{SrTiO}_{3}$ films grown at room temperature, $650{ }^{\circ} \mathrm{C}$, and $750{ }^{\circ} \mathrm{C}$ on ${ }^{18} \mathrm{O}$ exchanged $\mathrm{SrTiO}_{3}$ substrates by rf sputtering. (b) ${ }^{18} \mathrm{O}$ SIMS depth profiles of $\approx 40$-nm- thick $\mathrm{SrTiO}_{3}$ films grown at room temperature, 650,750 , and $875^{\circ} \mathrm{C}$ on ${ }^{18} \mathrm{O}$-exchanged $\mathrm{SrTiO}_{3}$ substrates by oxide $\mathrm{MBE}$ in $\mathrm{O}_{2}$, and (c) in a mixture of $\mathrm{O}_{2}+\mathrm{O}_{3}$ [16].

was not fast enough on the timescale to grow these films in order to compensate the ${ }^{16} \mathrm{O}$ supplied by the more reactive atmosphere provided by sputtering or ozone supported MBE. Also, the ${ }^{18 / 16} \mathrm{O}$ ratio in the films is quite different for each deposition technique. A very large ${ }^{18} \mathrm{O}$ concentration in the sputtered films would indicate the growth of initially oxygen deficient $\mathrm{SrTiO}_{3-x}$ and the missing oxygen is supplied by the substrate. At the largest $T_{\mathrm{S}}$, there is a competition between
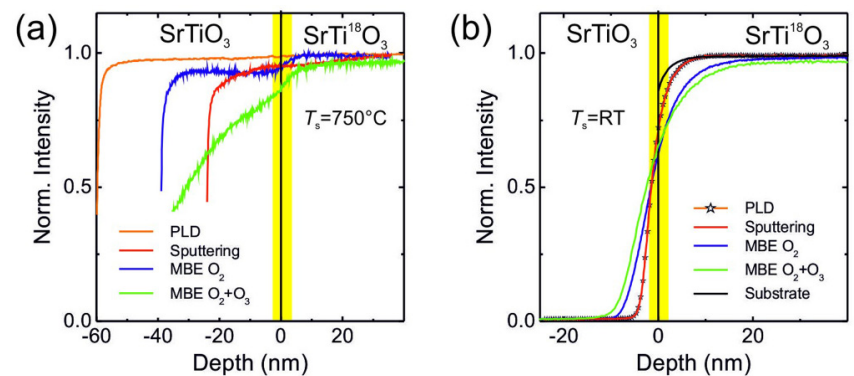

FIG. 4. Comparison of the different depth profiles for $\mathrm{SrTiO}_{3}$ films grown (a) at $750^{\circ} \mathrm{C}$ and (b) at room temperature by PLD, sputtering and $\mathrm{MBE}$ using an $\mathrm{O}_{2}$ and $\mathrm{O}_{2}+\mathrm{O}_{3}$ atmosphere. For comparison, the ${ }^{18} \mathrm{O}$ depth profile for the $\mathrm{SrTiO}_{3}$ substrate is shown.

the background ${ }^{16} \mathrm{O}$ and the ${ }^{18} \mathrm{O}$ from the substrate with some ${ }^{16} \mathrm{O}$ being supplied by the background. For MBE grown films with an $\mathrm{O}_{2}$ background, the incorporation of ${ }^{18} \mathrm{O}$ seems to be governed by the oxygen diffusion kinetic of the substrate. With increasing $T_{\mathrm{S}}$ more ${ }^{18} \mathrm{O}$ is supplied by the substrate and subsequently incorporated into the film. The same holds for MBE grown films with a more reactive oxygen background. Here, the reaction kinetics for the film formation is faster than the substrate is able to supply oxygen. Hence less ${ }^{18} \mathrm{O}$ is found in a film at any used $T_{\mathrm{S}}$ and some of the background ${ }^{16} \mathrm{O}$ is diffusing into the substrate.

The ${ }^{18 / 16} \mathrm{O}_{2}$ exchange at or near the surface also takes place for the $\mathrm{SrTiO}_{3}$ film deposition at room temperature irrespective of the deposition technique [Fig. 4(b)]. It is most pronounced for ozone supported MBE and the least for sputtering and PLD. As a reference, the ${ }^{18} \mathrm{O}$ depth profile of the substrate (black) is shown to indicate the oxygen exchange in $\mathrm{SrTiO}_{3}$ at room temperature for these films. The depth of the exchange is not in favor of a passive, but of a forced oxygen exchange. One possible source is the formation of an oxygen deficient $\mathrm{SrTiO}_{3-x}$ film during growth leading to a difference in the chemical potential of oxygen between the oxygen deficient film and the fully oxygenated substrate [44]. To compensate the resulting chemical potential difference some oxygen is pulled from the substrate to recompense the oxygen deficiency of the film.

Like for $\mathrm{SrTiO}_{3}$ grown on $\mathrm{SrTiO}_{3}$, a similar ${ }^{18} \mathrm{O}$ depth profile for $\mathrm{LaAlO}_{3}$ films grown by PLD on $\mathrm{SrTi}{ }^{16 / 18} \mathrm{O}_{3}$ at room temperature has been measured. Reanalyzing the ${ }^{18} \mathrm{O}$-depth profile (Fig. 2(c) from Ref. [30]), a similar deep-reaching ${ }^{18} \mathrm{O}$ depletion of the substrate is noted as shown in Fig. 1(b). Analogous to $\mathrm{SrTiO}_{3}, \mathrm{LaAlO}_{3}$ grown by PLD at room temperature is amorphous and for these kind of layers an electrically conducting interface has been reported [45] with electrical properties similar to epitaxially grown bilayers [4-6]. The formation of this conducting interface is explained by a redox reaction $[45,46]$. The depth-resolved measurements of the ${ }^{18} \mathrm{O}$ profile for the $\mathrm{LaAlO}_{3} / \mathrm{SrTiO}_{3}$ system indicates, that oxygen is actively taken in and out of the film-substrate structure. This observation therefore supports the assumption of an active process like a redox reaction in both $\mathrm{LaAlO}_{3} / \mathrm{SrTiO}_{3}$ and $\mathrm{SrTiO}_{3} / \mathrm{SrTiO}_{3}$ film-substrate systems where the films have been grown at ambient conditions. 
An interesting side aspect arises from the last observation of the forced oxygen exchange while growing a film, namely, that a substrate like $\mathrm{SrTiO}_{3}$ can have variable properties for growth at any given or used deposition temperature. If there is a dynamic exchange of oxygen taking place as it will be for any ion conductor [37], this will influence locally the chemistry as well as lattice parameters of the substrate-film interface and the expected strain state for the film to grow is not automatically correct [43]. In addition, these depth profile measurements also show why additional background oxygen is needed to supplement the lost oxygen of the substrate during a heating cycle that would otherwise lead to an electrically conducting $\mathrm{SrTiO}_{3-x}[47,48]$.

\section{CONCLUSIONS}

In summary, we have shown that the oxygen-substrate contribution is a significant factor when growing oxide thin films and has to be taken into the overall oxygen balance. Thin $\mathrm{SrTiO}_{3}$ films where deposited on ${ }^{18} \mathrm{O}$ exchanged $\mathrm{SrTiO}_{3}$ substrates using PLD, rf sputtering and oxide MBE and the ${ }^{18} \mathrm{O}$ diffusion profile was studied by ERDA and SIMS. For PLD grown films, an oxygen transfer between the substrate and the as-grown thin film has been observed even for a film grown at room temperature. This is in agreement with the observation of the growth of highly oxygen deficient
$\mathrm{SrTiO}_{3}$ films when deposited under vacuum conditions. The extraction and exchange of oxygen from the substrate is also seen for as-grown $\mathrm{SrTiO}_{3}$ films prepared by rf sputtering and oxide MBE; in particular for films grown in a more reactive oxygen environment where the oxygen composition of the ${ }^{18} \mathrm{O}$-exchanged substrate changes during the growth of the film and ${ }^{18} \mathrm{O}$ is partly replaced with ${ }^{16} \mathrm{O}$ up to a depth of several tens of $\mathrm{nm}$. These findings imply that the selected example of $\mathrm{SrTiO}_{3}$ as a substrate can be considered capricious in nature with respect to thin film growth. This will probably be equally applicable for oxides used as substrate materials where oxygen diffusion and oxygen chemistry at elevated temperatures plays a role [37].

\section{ACKNOWLEDGMENTS}

We acknowledge the help with, and discussion of sample and substrate preparation, and on oxygen diffusion in oxide crystals with C. M. Brooks, K. Conder, P. Droste, M. Esposito, J. Mannhart, I. Marozau, L. Maurel, D. Pergolesi, K. Peters, E. Pomjakushina, D. G. Schlom, D. Stender, and A. Wokaun. We also thank Chr. Bernhard and his group for providing the $\mathrm{YBa}_{2} \mathrm{Cu}_{3} \mathrm{O}_{7} / \mathrm{La}_{0.66} \mathrm{Ca}_{0.33} \mathrm{MnO}_{3}$ multilayer. This work was partially supported by the Swiss National Science Foundation (Project No. 200021-134577) and the Paul Scherrer Institute.
[1] D. B. Chrisey and J. R. Huber, Pulsed Laser Deposition of Thin Films (Wiley, New York, 1994), p. 609.

[2] D. H. Lowndes, D. B. Geohegan, A. A. Puretzky, D. P. Norton, and C. M. Rouleau, Synthesis of novel thin-film materials by pulsed laser deposition, Science 273, 898 (1996).

[3] C. W. Schneider and T. Lippert, Laser Processing of MaterialsFundamentals, Applications and Developments, in Springer Series in Material Science, edited by P. Schaaf (Springer, Berlin, 2010), pp. 89-112.

[4] A. Ohtomo and H. Y. Hwang, A high-mobility electron gas at the $\mathrm{LaAlO}_{3} / \mathrm{SrTiO}_{3}$ heterointerface, Nature (London) 427, 423 (2004).

[5] S. Thiel, G. Hammerl, A. Schmehl, C. W. Schneider, and J. Mannhart, Tunable quasi-two-dimensional electron gases in oxide heterostructures, Science 313, 1942 (2006).

[6] J. Mannhart and D. G. Schlom, Oxide Interfaces-An Opportunity for Electronics, Science 327, 1607 (2010).

[7] I. M. Dildar, D. B. Boltje, M. H. S. Hesselberth, J. Aarts, Q. Xu, H. W. Zandbergen, and S. Harkema, Non-conducting interfaces of $\mathrm{LaAlO}_{3} / \mathrm{SrTiO}_{3}$ produced in sputter deposition: The role of stoichiometry, Appl. Phys. Lett. 102, 121601 (2013).

[8] I. M. Dildar, M. Neklyudova, Q. Xu, H. W. Zandbergen, S. Harkema, D. Boltje, and J. Aarts, Growing $\mathrm{LaAlO}_{3} / \mathrm{SrTiO}_{3}$ interfaces by sputter deposition, AIP Adv. 5, 067156 (2015).

[9] J. P. Podkaminer, T. Hernandez, M. Huang, S. Ryu, C. W. Bark, S. H. Baek, J. C. Frederick, T. H. Kim, K. H. Cho, J. Levy, M. S. Rzchowski, and C. B. Eom, Creation of a two-dimensional electron gas and conductivity switching of nanowires at the $\mathrm{LaAlO}_{3} / \mathrm{SrTiO}_{3}$ interface grown by 90 degrees off-axis sputtering, Appl. Phys. Lett. 103, 071604 (2013).

[10] M. P. Warusawithana, C. Richter, J. A. Mundy, P. Roy, J. Ludwig, S. Paetel, T. Heeg, A. A. Pawlicki, L. F. Kourkoutis,
M. Zheng, M. Lee, B. Mulcahy, W. Zander, Y. Zhu, J. Schubert, J. N. Eckstein, D. A. Muller, C. S. Hellberg, J. Mannhart, and D. G. Schlom, $\mathrm{LaAlO}_{3}$ stoichiometry is key to electron liquid formation at $\mathrm{LaAlO}_{3} / \mathrm{SrTiO}_{3}$ interfaces, Nat. Commun. 4, 9 (2013).

[11] N. Reyren, S. Thiel, A. D. Caviglia, L. F. Kourkoutis, G Hammerl, C. Richter, C. W. Schneider, T. Kopp, A. S. Ruetschi, D. Jaccard, M. Gabay, D. A. Muller, J. M. Triscone, and J. Mannhart, Superconducting interfaces between insulating oxides, Science 317, 1196 (2007).

[12] A. Brinkman, M. Huijben, M. Van Zalk, J. Huijben, U. Zeitler, J. C. Maan, W. G. Van der Wiel, G. Rijnders, D. H.A. Blank, and $\mathrm{H}$. Hilgenkamp, Magnetic effects at the interface between non-magnetic oxides, Nat. Mater. 6, 493 (2007).

[13] H. M. Christen, J. Mannhart, E. J. Williams, and C. Gerber, Dielectric properties of sputtered $\mathrm{SrTiO}_{3}$ films, Phys. Rev. B 49, 12095 (1994).

[14] D. Fuchs, C. W. Schneider, R. Schneider, and H. Rietschel, High dielectric constant and tunability of epitaxial $\mathrm{SrTiO}_{3}$ thin film capacitors, J. Appl. Phys. 85, 7362 (1999).

[15] S. Kazuo, K. Masahiro, U. Akira, and Y. Kikuo, Homoepitaxial growth of $\mathrm{SrTiO}_{3}$ in an ultrahigh vacuum with automatic feeding of oxygen from the substrate at temperatures as low as $370{ }^{\circ}$ C, Jpn. J. Appl. Phys. 41, L269 (2002).

[16] C. M. Brooks, L. F. Kourkoutis, T. Heeg, J. Schubert, D. A. Muller, and D. G. Schlom, Growth of homoepitaxial $\mathrm{SrTiO}_{3}$ thin films by molecular-beam epitaxy, Appl. Phys. Lett. 94, 162905 (2009).

[17] M. Naito, H. Yamamoto, and H. Sato, Reflection high-energy electron diffraction and atomic force microscopy studies on homoepitaxial growth of $\mathrm{SrTiO}_{3}(001)$, Physica C 305, 233 (1998). 
[18] G. Koster, B. L. Kropman, G. Rijnders, D. H.A. Blank, and H. Rogalla, Quasi-ideal strontium titanate crystal surfaces through formation of strontium hydroxide, Appl. Phys. Lett. 73, 2920 (1998).

[19] H. N. Lee, H. M. Christen, M. F. Chisholm, C. M. Rouleau, and D. H. Lowndes, Strong polarization enhancement in asymmetric three-component ferroelectric superlattices, Nature (London) 433, 395 (2005).

[20] H. N. Lee, S. S. Ambrose Seo, W. S. Choi, and C. M. Rouleau, Growth control of oxygen stoichiometry in homoepitaxial $\mathrm{SrTiO}_{3}$ films by pulsed laser epitaxy in high vacuum, Sci. Rep. 6, 19941 (2016).

[21] A. P. Kajdos and S. Stemmer, Surface reconstructions in molecular beam epitaxy of $\mathrm{SrTiO}_{3}$, Appl. Phys. Lett. 105, 191901 (2014).

[22] T. Ohnishi, K. Shibuya, T. Yamamoto, and M. Lippmaa, Defects and transport in complex oxide thin films, J. Appl. Phys. 103, 103703 (2008).

[23] R. Groenen, J. Smit, K. Orsel, A. Vailionis, B. Bastiaens, M. Huijben, K. Boller, G. Rijnders, and G. Koster, Research Update: Stoichiometry controlled oxide thin film growth by pulsed laser deposition, APL Mater. 3, 070701 (2015).

[24] Z. Yu, R. Droopad, J. Ramdani, J. A. Curless, C. D. Overgaard, J. M. Finder, K. W. Eisenbeiser, J. Wang, J. A. Hallmark, and W. J. Ooms, Properties of epitaxial $\mathrm{SrTiO}_{3}$ thin films grown on silicon by molecular beam epitaxy, MRS Online Proc. Library Archive 567, 427 (1999).

[25] J. G. Mavroides, J. A. Kafalas, and D. F. Kolesar, Photoelectrolysis of water in cells with $\mathrm{SrTiO}_{3}$ anodes, Appl. Phys. Lett. 28, 241 (1976).

[26] J. H. Haeni, P. Irvin, W. Chang, R. Uecker, P. Reiche, Y. L. Li, S. Choudhury, W. Tian, M. E. Hawley, B. Craigo, A. K. Tagantsev, X. Q. Pan, S. K. Streiffer, L. Q. Chen, S. W. Kirchoefer, J. Levy, and D. G. Schlom, Room-temperature ferroelectricity in strained $\mathrm{SrTiO}_{3}$, Nature (London) 430, 758 (2004).

[27] S. Gerhold, Z. Wang, M. Schmid, and U. Diebold, Stoichiometry-driven switching between surface reconstructions on $\mathrm{SrTiO}_{3}(001)$, Surf. Sci. 621, L1 (2014).

[28] J. Mannhart and D. G. Schlom, Semiconductor physics: The value of seeing nothing, Nature (London) 430, 620 (2004).

[29] J. Chen, M. Döbeli, D. Stender, M. M. Lee, K. Conder, C. W. Schneider, A. Wokaun, and T. Lippert, Tracing the origin of oxygen for $\mathrm{La}_{0.6} \mathrm{Sr}_{0.4} \mathrm{MnO}_{3}$ thin film growth by pulsed laser deposition, J. Phys. D 49, 045201 (2016).

[30] C. W. Schneider, M. Esposito, I. Marozau, K. Conder, M. Doebeli, Y. Hu, M. Mallepell, A. Wokaun, and T. Lippert, The origin of oxygen in oxide thin films: Role of the substrate, Appl. Phys. Lett. 97, 192107 (2010).

[31] R. Pérez Casero, R. Gómez San Román, C. Maréchal, J. P. Enard, and J. Perrière, Laser ablation of oxides: study of the oxygen incorporation by ${ }^{18} \mathrm{O}$ isotopic tracing techniques, Appl. Surf. Sci. 96-98, 697 (1996).

[32] J. Chen, A. Palla-Papavlu, Y. Li, L. Chen, X. Shi, M. Döbeli, D. Stender, S. Populoh, W. Xie, A. Weidenkaff, C. W. Schneider, A. Wokaun, and T. Lippert, Laser deposition and direct-writing of thermoelectric misfit cobaltite thin films, Appl. Phys. Lett. 104, 231907 (2014).

[33] M. Döbeli, Characterization of oxide films by $\mathrm{MeV}$ ion beam techniques, J. Phys.: Condens. Matter 20, 264010 (2008).

[34] W. K. Chu, J. W. Mayer, and M. A. Nicolet, Backscattering Spectrometry (Academic Press, New York, 1978).

[35] L. R. Doolittle, A semiautomatic algorithm for Rutherford backscattering analysis, Nucl. Instrum. Methods Phys. Res., Sect. B 15, 227 (1986).

[36] H. Téllez, J. M. Vadillo, and J. J. Laserna, Development of an energy-resolved method for SIMS in-depth analysis of metalpolymer interfaces, Surf. Interface Anal. 43, 632 (2011).

[37] D. Stender, S. Heiroth, T. Lippert, and A. Wokaun, A comparison between micro-Raman spectroscopy and SIMS of beveled surfaces for isotope depth profiling, Solid State Ion. 253, 185 (2013).

[38] R. A. De Souza, Oxygen diffusion in $\mathrm{SrTiO}_{3}$ and related perovskite oxides, Adv. Funct. Mater. 25, 6326 (2015).

[39] V. Metlenko, A. H. H. Ramadan, F. Gunkel, H. Du, H. Schraknepper, S. Hoffmann-Eifert, R. Dittmann, R. Waser, and R. A. De Souza, Do dislocations act as atomic autobahns for oxygen in the perovskite oxide $\mathrm{SrTiO}_{3}$ ? Nanoscale 6, 12864 (2014).

[40] K. K. Adepalli, J. Yang, J. Maier, H. L. Tuller, and B. Yildiz, Tunable oxygen diffusion and electronic conduction in $\mathrm{SrTiO}_{3}$ by dislocation-induced space charge fields, Adv. Funct. Mater. 27, 1700243 (2017).

[41] H. Schraknepper, T. E. Weirich, and R. A. De Souza, The blocking effect of surface dislocations on oxygen tracer diffusion in $\mathrm{SrTiO}_{3}$, Phys. Chem. Chem. Phys. 20, 15455 (2018).

[42] R. Wang, Y. Zhu, and S. M. Shapiro, Structural Defects and the Origin of the Second Length Scale in $\mathrm{SrTiO}_{3}$, Phys. Rev. Lett. 80, 2370 (1998).

[43] E. Gilardi, A. Fluri, T. Lippert, and D. Pergolesi, Real-time monitoring of stress evolution during thin film growth by in situ substrate curvature measurement, J. Appl. Phys. 125, 082513 (2019).

[44] J. Zhu, J.-W. Lee, H. Lee, L. Xie, X. Pan, R. A. De Souza, C.-B. Eom, and S. S. Nonnenmann, Probing vacancy behavior across complex oxide heterointerfaces, Sci. Adv. 5, eaau8467 (2019).

[45] Y. Chen, N. Pryds, J. E. Kleibeuker, G. Koster, J. Sun, E. Stamate, B. Shen, G. Rijnders, and S. Linderoth, Metallic and insulating interfaces of amorphous $\mathrm{SrTiO}_{3}$-based oxide heterostructures, Nano Lett. 11, 3774 (2011).

[46] A. B. Posadas, K. J. Kormondy, W. Guo, P. Ponath, J. GelerKremer, T. Hadamek, and A. A. Demkov, Scavenging of oxygen from $\mathrm{SrTiO}_{3}$ during oxide thin film deposition and the formation of interfacial 2DEGs, J. Appl. Phys. 121, 105302 (2017).

[47] A. Kalabukhov, R. Gunnarsson, J. Börjesson, E. Olsson, T. Claeson, and D. Winkler, Effect of oxygen vacancies in the $\mathrm{SrTiO}_{3}$ substrate on the electrical properties of the $\mathrm{LaAlO}_{3} / \mathrm{SrTiO}_{3}$ interface, Phys. Rev. B 75, 121404 (2007).

[48] P. P. Balakrishnan, M. J. Veit, U. S. Alaan, M. T. Gray, and Y. Suzuki, Metallicity in $\mathrm{SrTiO}_{3}$ substrates induced by pulsed laser deposition, APL Mater. 7, 011102 (2019). 